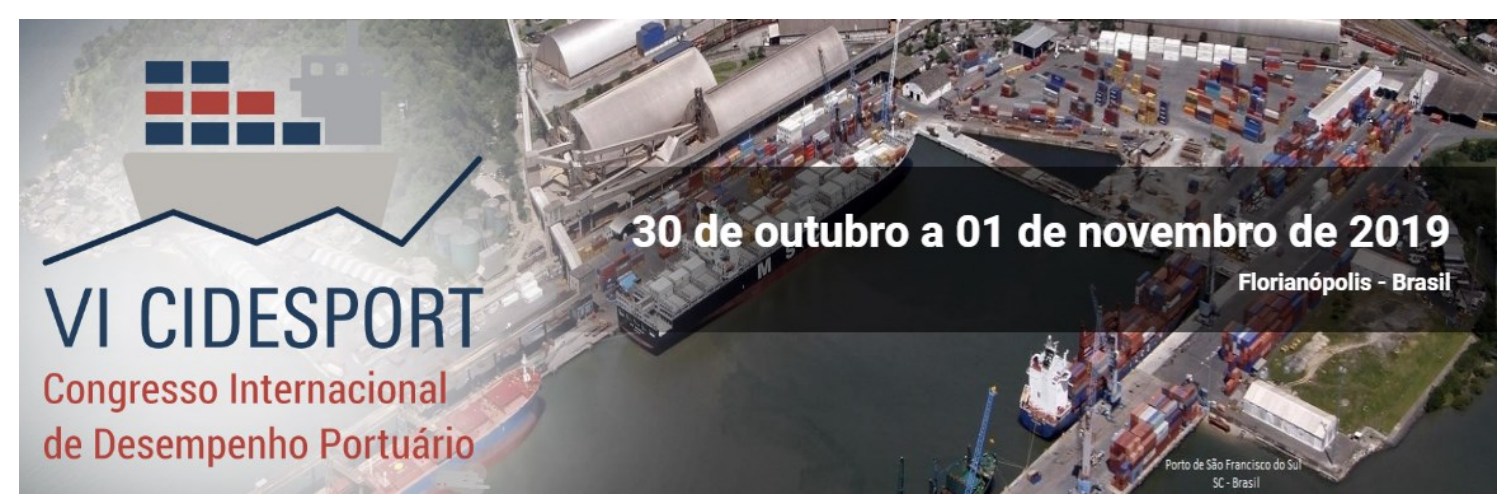

\title{
ANÁLISE DE INDICADORES DE DESEMPENHO EM UM PORTO DE SANTA CATARINA
}

Felipe Peron Goulart Universidade Federal de Santa Catarina

Evandro Moritz Luz Universidade Federal de Santa Catarina Gabriel Fernandes Pereira
Universidade Federal de Santa Catarina Luis Eduardo Correa de Sousa Vieira Universidade Federal de Santa Catarina

\section{Lucas Silva Rodrigues Universidade Federal de Santa Catarina}

\begin{abstract}
Resumo: O setor portuário catarinense é bastante forte e relevante no cenário nacional, sendo assim é necessário que os portos utilizem indicadores de desempenho para se manterem competitivos frente a concorrência. O presente artigo traz uma comparação entre os níveis de medição de indicadores de desempenho tradicionais e as adaptações no âmbito portuário, bem como a validação da importância de indicadores observados na literatura para um grande porto de Santa Catarina. Para tanto, aplicou-se um formulário junto ao porto $\mathrm{Y}$, com a finalidade de compreender a sua realidade e validar a usabilidade de indicadores encontrados na literatura para o porto em questão. Após análise desses indicadores, perceberam-se diferenças entre os níveis tradicionais, os encontrados na literatura, e os utilizados pelo mesmo. Assim foi realizado um estudo comparativo para entender melhor a relação entre as classificações dos indicadores. Por fim pode-se ressaltar que o estudo se limitou ao contato com apenas um porto e estudos posteriores podem ser realizados para o complemento deste.
\end{abstract}

Palavras-chave: Porto. Indicadores. Logística portuária.

\section{INTRODUÇÃO}

A competição dentro das mais diversas áreas de negócio, vem ganhando força e destaque estratégico perante empresas e players das mais diversas cadeias de comércio mundial. Segundo Kotler e Armstrong (2003, p. 45) para ser bem-sucedidas no atual mercado competitivo, as empresas devem estar voltadas para o cliente conquistando-o dos concorrentes e mantendo-o por lhe entregar valor superior. Entretanto, para poder satisfazer os consumidores, a empresa deve antes entender

\footnotetext{
*A revisão gramatical, ortográfica, ABNT ou APA foi realizada pelos autores.
} 
suas necessidades e desejos. A busca para atender as premências dos supostos consumidores, gera a necessidade de uma infraestrutura interna e um conhecimento vasto do real propósito de atuação da organização.

Os portos são responsáveis pela movimentação de grande parte dos produtos em âmbito mundial, sendo considerados influenciadores diretos na satisfação e fidelização do cliente, este a fim de entregar seus pedidos com qualidade. Atualmente o Brasil conta com cerca de 35 portos organizados e 156 terminais de uso privado (TUP) (AET, 2018), onde destes movimentaram cerca de 1,117 bilhão de toneladas (ANTAQ, 2018). Pela abundante e ininterrupta movimentação nos portos, para atender as demandas com qualidade, se faz necessário uma gestão efetiva de todas as partes envolvidas, tanto nas operações quanto nas estratégias da organização como um todo. Alinhando constantemente com os objetivos almejados pela entidade.

De acordo com Takashina e Flores (2005), indicadores são formas de representação quantificáveis das características de produtos e processos. Estes são considerados ferramentas indispensáveis para um controle eficiente das operações, processos e do próprio mercado. Entretanto pelo vasto número de processos dentro das organizações, estas ferramentas tomam as mais diversas segmentações, dificultando em muitos casos a análise da própria atividade.

Não apenas as divisões dos indicadores são considerados uma problematização na aplicabilidade desta ferramenta, mas também a autenticidade com que os dados coletados pelos mesmos são condizentes com a realidade. Em virtude disto, esta pesquisa tem o propósito de comparar classificações literárias e as práticas de utilização de indicadores portuários. Desta forma, aprofundou-se o estudo em um determinado porto catarinense, comparando a atividade prática com as pesquisas científicas apuradas. Com isso abrem-se questionamentos com relação às representações e veracidade da aplicação destas medidas, fomentando um mercado muito representativo para a satisfação do consumidor final.

\section{REFERENCIAL TEÓRICO}

\subsection{Porto}

Portos são áreas as quais existem facilidades para ancoragem ou atracação de navios. Além disso, devem apresentar equipamentos para transferência de bens do navio para o cais, ou vice-versa, bem como de um navio para outro. Em outras palavras, porto é uma localidade que permita que ocorra uma relação entre navio e costa (ALDERTON; SAIEVA, 2016). Uma outra definição de portos seria, segundo Júnior et al. (2008), de que o mesmo se encaixa com um dos elos pertencentes da cadeia de transporte, cujo objetivo é integrar as sociedades através da movimentação de bens, mercadorias, a fim de alimentar a economia global.

De acordo com KEEDI (2011), o papel dos portos dentro das cadeias de suprimento é estratégico e de suma importância, uma vez que a maioria das exportações utilizam o transporte marítimo internacional. Na Figura 1, adaptada de Pettit e Beresford (2009), fica compreendido a função do porto segundo a ótica das cadeias de suprimento, também é destacado como o porto evoluiu nos últimos 40 anos em termos de agregar valor e integralizar a cadeia de suprimentos. 
VI CIDESPORT/2019

Congresso Internacional

de Desempenho Portuário

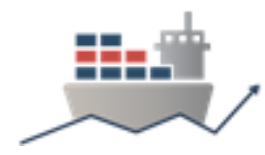

Figura 1 - A integração de portos na cadeia global de suprimentos

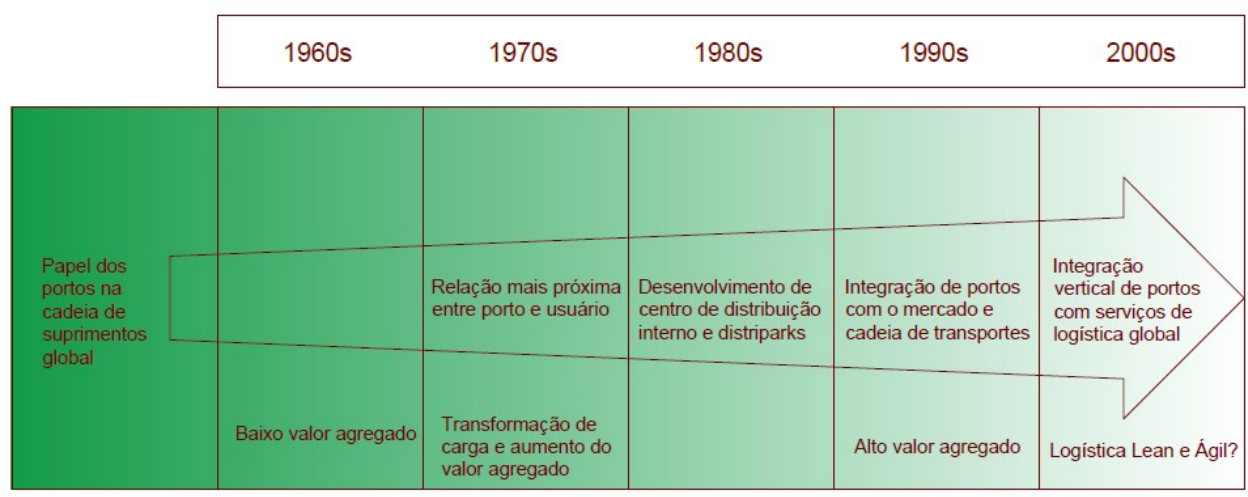

Fonte: Pettit e Beresford (2009), adaptado.

Segundo Carbone e Martino (2003), o papel dos portos é de coordenar e gerir os fluxos de materiais e informações, colocando o transporte como uma parte da cadeia de suprimentos. Para a evolução de portos como plataformas logísticas, é necessário considerar também as necessidades dos clientes, ou seja as empresas que enviam e recebem materiais pelo porto, além dos já tradicionais operadores logísticos e companhias de navegação. Eles acrescentam ainda que a competitividade do porto não fica limitada apenas a sua eficiência operacional e infraestrutura, mas todas as conexões com a cadeia de suprimentos. Assim a competitividade de um porto está cada vez mais ligada a coordenação de fatores externos e controle da cadeia de suprimentos como um todo.

Complementando a definição acima, Bichou e Gray (2004) afirmam que os portos exercem um papel fundamental na integração entre três canais: canal de distribuição logístico, de comércio e de suprimentos. O canal de distribuição logística é composto em sua essência por especialistas que tornam mais fácil o progresso eficiente de cargas no decorrer de uma cadeia de suprimentos. Um exemplo disso são os transportadores marítimos. Para este canal os portos são um elo essencial, visto que auxiliam na intersecção de transporte multimodal/intermodal, exercendo, para movimentações de mercadorias e passageiros, o papel de um centro logístico. Os outros dois canais, de comércio e suprimentos, relacionam-se à propriedade de bens, os quais movem-se por entre um sistema de organizações que se relacionam entre si. Nestes três canais, o porto pode ser considerado como o centro no qual correm as negociações. Dessa forma, portos tornam-se um dos poucos pontos da rede capazes de concentrar vários membros de uma cadeia de suprimento.

Para Cullinane e Song (2002), os portos constituem conexões críticas entre os mais diversos elos da cadeia de distribuição, exigindo que os portos se desenvolvam continuamente em sua infraestrutura para o suporte eficiente necessário nas cadeias de suprimentos. Em complemento a esta informação, o nível de eficiência e performance influenciam diretamente a competitividade do país no qual se situam. Logo, a infraestrutura portuária deve desenvolver-se em conjunto com a indústria nacional.

\subsection{Logística portuária}


A logística vem evoluindo e ganhando representatividade cada vez maior nos mais diversos ambientes de negócio. Não apenas conceitualmente, mas também auferindo dinamicidade e gerenciabilidade na cadeia. Em termos gerais o gerenciamento logístico é considerada parte da gestão da cadeia de suprimentos que planeja, implementa e controla, eficaz e eficientemente, o fluxo bidirecional (para frente e para trás) e armazena mercadorias, serviços, além de informações relacionadas, entre o ponto de origem e o ponto de consumo com o intuito de atender os requisitos dos cliente (Council of Supply Management Professionals, 2019). Para a realização de um bom desempenho gerencial da cadeia logística se faz necessário uma coordenação eficiente da matriz de transportes das nações. Com isso as organizações portuárias ganham papel fundamental, muito também por movimentar grande parte das mercadorias do país, 1,117 bilhão de toneladas (ANTAQ, 2018).

De maneira similar a plena movimentação e operacionalização das cargas dentro das imediações portuárias, são consideradas logística portuária. Levando então em consideração as exigências dos clientes, todas as atividades realizadas pelas organizações portuárias devem ser integradas e eficientes, sendo estas constituintes da gestão portuária da instituição. A gestão portuária definida como, a interação efetiva dos subsistemas portuários e compreende um conjunto de atividades e de processos sequenciais, desde a chegada/saída das cargas via terrestre até seu embarque/desembarque nos navios (CUTRIM, 2017), torna-se então diferencial para os portos e terminais portuários.

Frederick Reichheld (2001) acredita que a única maneira de uma empresa desenvolver uma base de clientes fiéis é construir relacionamentos a partir de sólidos compromissos com os funcionários responsáveis pelo atendimento a esses clientes. Isso é o que fazem as companhias que chama de "líderes em lealdade". Visto a importância no comércio internacional do país, as entidades portuárias, necessitam então de uma constante evolução nos quesitos produtividade, agilidade e qualidade das entregas realizadas.

\subsection{Carga conteinerizada}

O container exerce um papel importante na logística portuária, facilitando a movimentação dos mais diversos tipos de cargas no comércio internacional. Como uma embalagem que tradicionalmente é constituída em aço, alumínio ou fibra, é utilizada para o transporte unitizado de mercadorias, destinada para sistemas modernos de distribuição, e possuindo diversos tamanhos padronizados e normalizados para o transporte internacional (KEEDI; MENDONÇA, 2003; BALLOU, 2006).

Rojas (2014) descreve que em operações de logística integrada, o principal equipamento é o contêiner. Ele facilita vários tipos de combinações de transportes multimodais, pois a carga acondicionada em contêineres não exige manuseios custosos e possibilita o serviço porta a porta quando a combinação de modais utiliza transportes terrestres, Levinson (2008) reforça ao concluir que o container trouxe um novo padrão de unitização de cargas para o comércio internacional.

\subsection{Indicadores de desempenho}

Os indicadores de desempenho representam um conjunto de métricas que visam medir os aspectos organizacionais mais críticos da empresa. Baseiam-se em informações coletadas com o máximo de acuracidade possível e devem ser validadas 
por todos os agentes envolvidos de modo a atingir uma meta pré-estabelecida (BELMONTE; BOTTER, 2015). No mesmo viés Fortuin (1994) define os indicadores de desempenho como as variáveis que indicam a eficácia, efetividade e eficiência de um processo, sistema, ou parte de um sistema, comparado a um valor de referência.

Ainda segundo a ANTAQ (2003), os indicadores de desempenho possuem a função de avaliar a qualidade dos serviços oferecidos por uma empresa, bem como a satisfação dos usuários e clientes. Também permite relacionar qualidade dos serviços com as necessidades dos usuários, avaliando resultados e auxiliando na tomada de decisões. Além disso, os indicadores de desempenho tornam possível comparações internas da empresa, analisando o desempenho do indicador ao longo do tempo, e externas, realizando comparações com outras organizações.

O nível de medição dos indicadores de desempenho pode ser subdivididos em estratégico, tático e operacional (BORNIA et al., 2010). Segundo a UNCTAD (1985), o nível estratégico está relacionado ao investimento em melhorias em infraestrutura, visando o atingimento de objetivos a longo prazo. Já o tático está ligado a questões administrativas, aperfeiçoando os processos através da compra de maquinário e melhoria de layout, por exemplo. Este nível é planejado para o período de um a cinco anos, sendo considerado de médio prazo. Já o operacional está ligado às atividade diárias e respostas imediatas, mantendo o desempenho do porto. Seu planejamento é realizado para alguns dias ou semanas, enquadrando-se no curto prazo.

Figura 2 - Pirâmide divisão/classificação de indicadores.

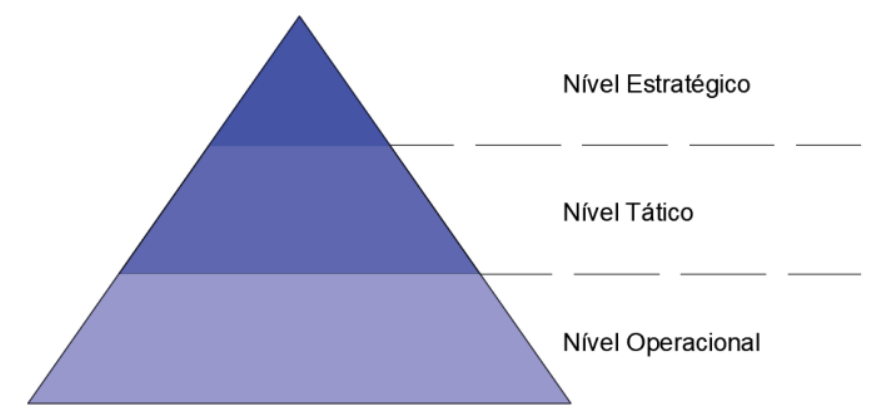

Fonte: Adaptado de Martins e Neto (1998).

A divisão tradicional dos níveis de indicadores de desempenho fornece uma visão focada na eficiência do porto, mas, atualmente, nota-se a necessidade de se analisar os indicadores sob o ponto de vista da qualidade das operações, com a finalidade de atingir os objetivos estratégicos da empresa (BERESFORD, PETTIT E WOO, 2011).

\subsection{Atividade portuária catarinense}

De acordo com De Oliveira Rocha et al. (2011) o estado de Santa Catarina possui um setor exportador bastante forte e dinâmico. Um fator determinante para este fato seria a interface logística de exportação do estado que conta com ótimas condições da faixa litorânea para o atlântico e boa infraestrutura rodoviária conectando as regiões produtoras, com as regiões portuárias, em especial os portos de Itajaí, Navegantes, São Francisco do Sul e Itapoá.

Segundo dados da Agência nacional de transportes aquaviários, a ANTAQ, em 2018 os portos catarinenses transportaram aproximadamente 45 milhões de toneladas de carga, sendo que destas, cerca de $45 \%$ ou pouco mais de 20 milhões 
VI CIDESPORT/2019

Congresso Internacional

de Desempenho Portuário

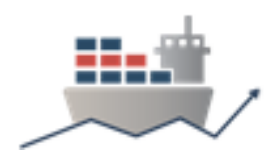

de toneladas foram em contêineres. Conforme evidenciado na figura 1 , os portos privados recebem grande destaque, transportando $75,1 \%$ das cargas conteinerizadas catarinenses, sendo $39,7 \%$ no porto de Navegantes e 35,3\% no porto de Itapoá. Os portos públicos relevantes são de Itajaí e Imbituba com $24,9 \%$ dos movimentos de contêineres. Desta maneira, conforme os dados da ANTAQ (2018) o porto Y é o porto catarinense mais relevante se tratando de contêineres.

Figura 3 - Movimentação de contêineres em Santa Catarina em toneladas.

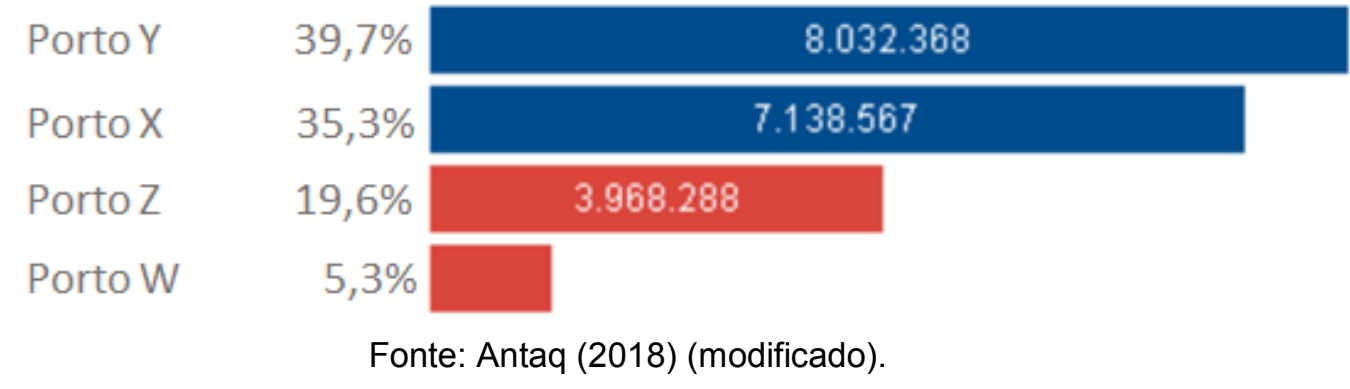

Ainda segundo a ANTAQ (2018), as movimentações de contêineres são pouco mais de $60 \%$ de embarcação, ou seja, a exportação de cargas conteinerizadas em Santa Catarina é maior que a importação. Em relação ao tipo de carga movimentada as que possuem maior destaque são: $19 \%$ de madeira e carvão vegetal, $16 \%$ de carnes, $8,3 \%$ de plásticos, $4,1 \%$ cereais e diversos outros tipos de carga com menor relevância.

Figura 4: Sentido do movimento dos contêineres em toneladas.

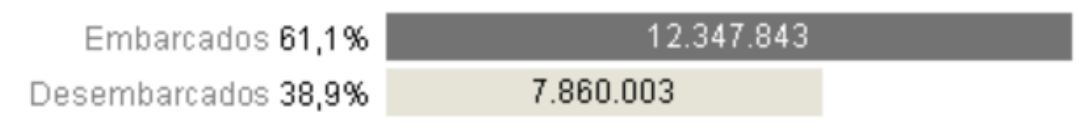

Fonte: Antaq (2018)

\section{PROCEDIMENTO METODOLÓGICO}

A pesquisa aqui desenvolvida tem como objetivo comparar a classificação teórica e prática de indicadores no meio portuário. Será contraposto divisões clássicas de indicadores, que, conforme citado por Bornia et al. (2010), são divididos em operacional, tático e estratégico, com a classificação feita por outros autores, bem como com aquela realizada pelo porto $\mathrm{Y}$, de Santa Catarina, sustentando análises com base nos indicadores deste porto.

A etapa inicial possuiu como finalidade a construção de um embasamento teórico do trabalho. Deste modo realizou-se a pesquisa e subsequente leitura de artigos e materiais acadêmicos no assunto. A fim de selecionar as literaturas, as bases de dados Scopus e Emerald foram consultadas, partindo do princípio de se construir uma base teórica para o seu desenvolvimento a partir de seleção de artigos pertinentes. Após levantamento dos materiais os quais englobam o assunto estudado, foi realizado um refinamento a fim das salientar literaturas representativas para a pesquisa. Dentre estas, onze artigos nas bases de pesquisa, sobre indicadores logístico portuários, nacionais e internacionais, foram elencados, propiciando uma capacidade de análise mais profunda sobre os mesmos. Para nortear a busca dos 
VI CIDESPORT/2019

Congresso Internacional

de Desempenho Portuário

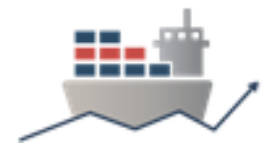

artigos para leitura, foram elencadas as seguintes palavras-chave: indicadores portuários, logística portuária, portos, portos em Santa Catarina. Dessa forma, os seguintes artigos serviram como base para a próxima etapa de construção do artigo:

Tabela 1: Artigos analisados.

\begin{tabular}{|c|c|c|}
\hline Título & Autor(es) & Ano \\
\hline $\begin{array}{l}\text { Port evolution and performance } \\
\text { in changing logistics } \\
\text { environments. }\end{array}$ & $\begin{array}{c}\text { Su-Han Woo; } \\
\text { Stephen Pettit; } \\
\text { Anthony K.C. Beresford }\end{array}$ & 2011 \\
\hline $\begin{array}{l}\text { Port performance measurement } \\
\text { in the context of port choice: an } \\
\text { MCDA approach. }\end{array}$ & $\begin{array}{l}\text { Jafar Rezaei; } \\
\text { Linde van Wulfften Palthe; } \\
\text { Lori Tavasszy; } \\
\text { Bart Wiegmans; } \\
\text { Frank van der Laan }\end{array}$ & 2018 \\
\hline $\begin{array}{l}\text { Properties of performance } \\
\text { indicators in operations } \\
\text { management. }\end{array}$ & $\begin{array}{l}\text { F. Franceschini; } \\
\text { M. Galetto; } \\
\text { D. Maisano; } \\
\text { L. Mastrogiacomo }\end{array}$ & 2007 \\
\hline $\begin{array}{l}\text { Operational performance of } \\
\text { terminals of containers. }\end{array}$ & $\begin{array}{l}\text { Maria Cristina Fogliatti de Sinay; } \\
\text { Michelly Gonçalves Fernandes }\end{array}$ & 2010 \\
\hline $\begin{array}{l}\text { Modernização da gestão } \\
\text { portuária e planejamento } \\
\text { operacional integrado por meio } \\
\text { de indicadores de desempenho. }\end{array}$ & João Henrique Vieira & 2018 \\
\hline $\begin{array}{l}\text { Método dos indicadores de } \\
\text { desempenho proposto pela } \\
\text { ANTAQ: uma aplicação ao } \\
\text { terminal portuário de Pecém. }\end{array}$ & $\begin{array}{c}\text { Ciro Marques Arruda; } \\
\text { Ernesto Ferreira Nobre Júnior; } \\
\text { Petronio Sá Benevides Magalhães }\end{array}$ & 2008 \\
\hline $\begin{array}{l}\text { Port logistics: optimization model } \\
\text { study. }\end{array}$ & $\begin{array}{l}\text { Kamal Lakhmas; } \\
\text { Abdelfettah Sedqui }\end{array}$ & 2018 \\
\hline $\begin{array}{l}\text { Integrated performance } \\
\text { measurement systems: a } \\
\text { development guide. }\end{array}$ & $\begin{array}{l}\text { Umit S. Bititci; } \\
\text { Allan S. Carrie; } \\
\text { Liam McDevitt }\end{array}$ & 1997 \\
\hline $\begin{array}{l}\text { Análise da eficiência portuária } \\
\text { em companhias docas com } \\
\text { vínculo com o Governo Federal. }\end{array}$ & $\begin{array}{c}\text { Cleyton de Oliveira Ritta; } \\
\text { Rodrigo Barraco Marassi; } \\
\text { Emma Taliani Castelló; } \\
\text { Fabrícia Silva da Rosa }\end{array}$ & 2017 \\
\hline
\end{tabular}


VI CIDESPORT/2019

Congresso Internacional

de Desempenho Portuário

Management Control Systems in port waste management:

Evidence from Italy.

A logistic and supply chain management approach to port performance measurement.
Assunta Di Vaioa;

Luisa Varrialeb;

Lourdes Trujilloc

Khalid Bichou;

Richard Gray
2018

2004

Fonte: Os autores.

Em seguida, realizou-se o método de brainstorming que, segundo Minicucci (2001), é uma técnica utilizada para geração de ideias, normalmente utilizado em etapas de planejamento. Neste método, realizado com base nas literaturas analisadas na etapa anterior, elencaram-se possíveis indicadores logísticos, classificados como estratégicos, táticos ou operacionais, que mais poderiam se adequar a realidade de um porto, bem como a maneira de calculá-los. Com o objetivo de validar os indicadores levantados durante o brainstorming, efetuou-se contato com o porto $\mathrm{Y}$ e, dessa forma, foi elaborado um estudo de campo. Para Berto et al. (1999), estudo de campo é um método de pesquisa executado com base em dados de campo, sem estruturação formal do método de pesquisa.

Por meio deste contato com o porto, foi disponibilizado para o presente artigo uma planilha com dados sobre os indicadores do porto. Estes dados contam a maneira como a empresa faz a divisão de seus indicadores, os principais indicadores utilizados para a gestão interna do porto e gestão geral do grupo de investidores que atuam na empresa, bem como a maneira de calculá-los. Posteriormente, comparou-se os indicadores levantados durante o brainstorming, e suas fórmulas, com aqueles fornecidos, juntamente com as formas de classificação dos mesmos. Com essas análises realizadas, a equipe da pesquisa norteou suas atividades para um estudo comparativo que, segundo Przeworski e Teune (1970), é uma investigação onde mais de um nível de análise é possível, sendo as unidades de observação para cada um destes níveis denominadas variáveis de contexto. Este estudo foi desenvolvido entre a estrutura clássica de divisão de indicadores, a estratégia de divisão utilizada por outros portos do planeta e com relação ao porto estudado.

Como resultado deste estudo de caso, construiu-se uma proposta de classificação de indicadores. Esta proposta teve como suporte às análises entre os três cenários anteriormente comparados, de maneira a relacionar questões teóricas às práticas. 
VI CIDESPORT/2019

Congresso Internacional

de Desempenho Portuário

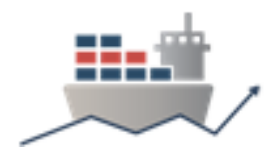

Figura 5: Metodologia de pesquisa

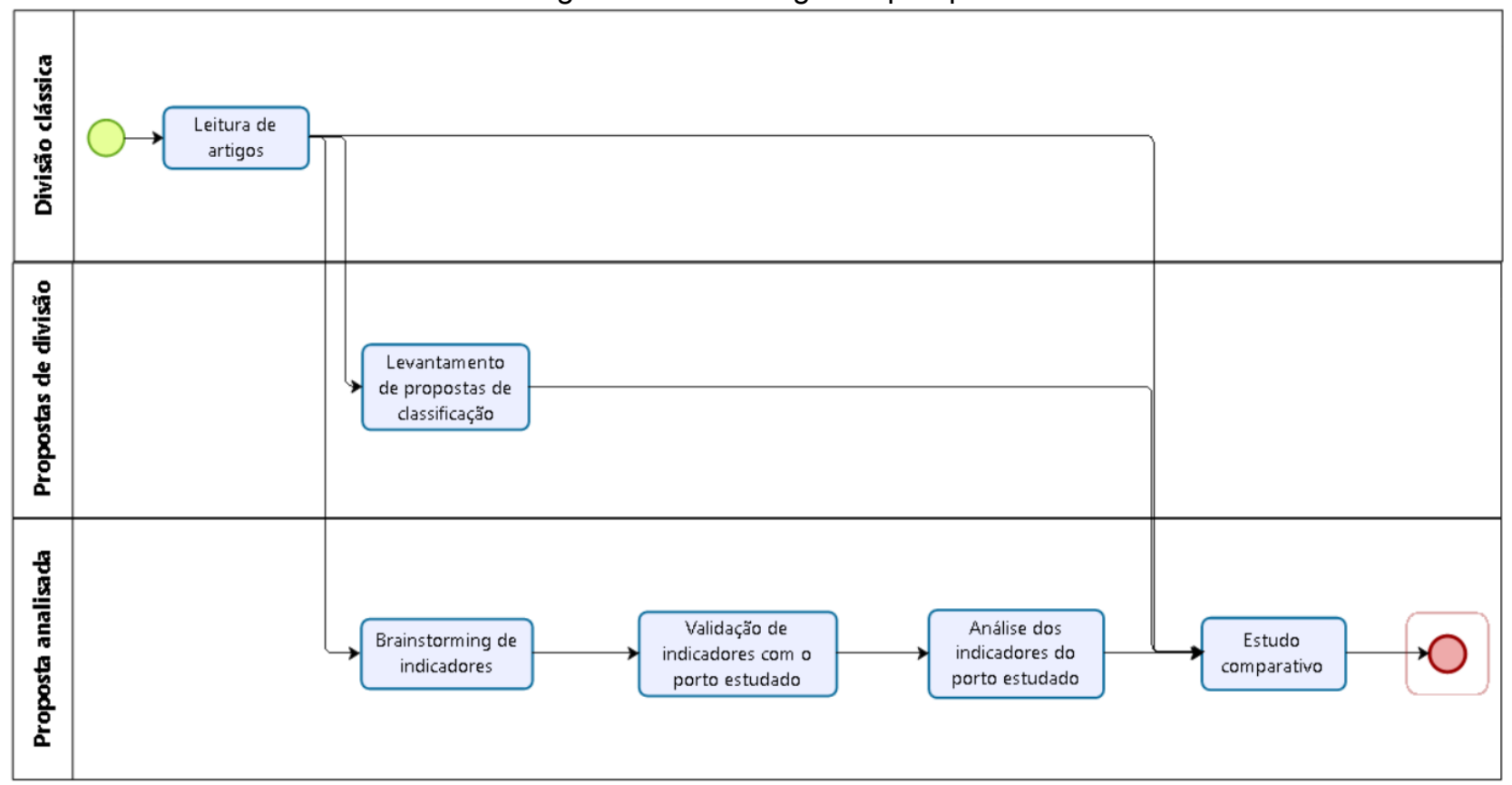

Fonte: Os autores.

\section{DESENVOLVIMENTO}

Muitas vezes a gestão pode se tornar um diferencial para qualquer negócio. Pela intensa competitividade do mercado, o cumprimento de metas e entregas se faz cada vez mais representativo para o crescimento e amadurecimento no ambiente externo. Segundo Mohrman e Mohrman (1995) é fundamental para a sobrevivência das organizações que estas consigam gerir seus recursos de maneira eficiente e que sejam capazes de mudar rapidamente de acordo com o seu mercado e necessidades dos seus clientes, gerando inovações que tragam vantagens competitivas, em relação aos seus concorrentes, possibilitando assim, sua continuidade e crescimento. Com isso, a utilização de métricas e indicadores ganha destaque estratégico nos inúmeros meios de gestão.

Para as estruturas portuárias não é diferente, a necessidade de adaptação e um gerenciamento interno eficiente é primordial. Uma diferenciação competitiva que amplia as movimentações e crescimento do negócio. Ao se considerar divisões iniciais, atrela-se muitas métricas em níveis hierárquicos diferentes, representando ações e estratégias de controle diversos, entre as mais heterogêneas formas de negócio. Nos dias de hoje, o porto catarinense escolhido para este estudo se caracteriza por ser eficiente e representativo no contexto nacional.

Localizado no estado de Santa Catarina, o porto Y é uma empresa focada soluções logísticas, principalmente as que envolvem desembarque, armazenamento e embarque de cargas conteinerizadas. Representando uma área de $377.000 \mathrm{~m}^{2}$, a estrutura do porto conta com $900 \mathrm{~m}$ de cais, 3 berços de atracação e cerca de 2.000 tomadas reefers fixas, desta forma é considerado um importante movimentador de cargas. Com uma estrutura interna bem organizada, o porto $Y$ emprega cerca de 1,3 mil trabalhadores diretos e é responsável por $50 \%$ da arrecadação de imposto sobre serviços (ISS), o que demonstra sua significativa representatividade para a economia do município. Sua representatividade é reafirmada ao se considerar dados mais 


\section{CIDESPORT/2019}

\section{Congresso Internacional}

de Desempenho Portuário

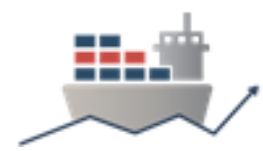

quantitativos das movimentações realizadas pelo mesmo. Muito por tamanha importância não apenas em âmbitos municipais como estaduais, $O$ porto $Y$ transparece proeminência no que diz questão a estratégias de crescimento e desenvolvimento, assim como em qualidade e intensidade de movimentação de carga.

Muito deste constante crescimento do porto diz respeito a eficiente gestão estratégica e estabelecimento de métricas apropriadas e adaptáveis às mudanças do mercado. Ao se considerar as divisões designadas pelo porto $\mathrm{Y}$.

Entretanto pela necessidade de adaptabilidade dos portos às mais diversas formas de medição e estratégias adotadas, os indicadores tendem a variar constantemente. Tratando em muitos casos de forma mais eficiente os dados com os quais se deseja trabalhar, evidenciando mais nitidamente os pontos de melhoria nos processos e mecanismos de gestão.

A tabela de indicadores abaixo, foi desenvolvida pelos autores com base no brainstorming realizado no início da construção do artigo, bem como suas formas de cálculo e classificação conforme a divisão clássica feita por Bornia et al. (2010). Estes indicadores foram então validados em contato com o porto $\mathrm{Y}$, conforme a aplicação do indicador para a sua realidade. A validação incluiu também as classificações de nível utilizadas e suas formas de cálculo que eram diferentes das propostas. Outros indicadores levantados, que o porto considerou como não relevantes, foram excluídos do estudo como: Custos de atraso dos navios, porcentagem de utilização de maquinário e tempo médio de permanência do container no porto.

Tabela 2: Tabela de indicadores.

\begin{tabular}{|c|c|c|c|}
\hline Indicador & Cálculo & Nível estudado & Nível real \\
\hline $\begin{array}{l}\text { Custo logístico por } \\
\text { contêiner }\end{array}$ & $\frac{\text { Custo total logística }}{\text { Quantidade de contêiner }}$ & Estratégico & Estratégico \\
\hline Lucro mensal & Lucro & Estratégico & Estratégico \\
\hline Custo de mão-de-obra & $\frac{\text { Custo com funcionários }}{\text { Número de funcionários }}$ & Estratégico & Gerencial \\
\hline $\begin{array}{l}\text { Quantidade de mão de } \\
\text { obra envolvida }\end{array}$ & Número de colaboradores envolvidos & Tático & Gerencial \\
\hline $\begin{array}{l}\text { Tempo médio de } \\
\text { armazenagem }\end{array}$ & Tempo que o container permanece no pátic & Tático & Gerencial \\
\hline $\mathrm{MPH}$ & Movimentos por hora & Tático & Estratégico \\
\hline Taxa de ocupação do pátio & $\frac{\text { Quantidade de container estocados }}{\text { Quantidade máxima }}$ & Tático & Processo \\
\hline $\begin{array}{l}\text { Quantidade acidentes de } \\
\text { trabalho }\end{array}$ & Número de acidentes dentro da área portu & Tático & Estratégico \\
\hline $\begin{array}{l}\text { Porcentagem de mão-de- } \\
\text { obra afastada }\end{array}$ & $\frac{\text { Número de funcionários a fastados }}{\text { Número total de funcionários }}$ & Tático & Estratégico \\
\hline
\end{tabular}




\section{Fonte: Os autores.}

Os métodos de cálculo da tabela 2 estão em sua maioria de acordo com a maneira de medição do porto, apenas dois indicadores diferem, são eles: Quantidade de acidentes de trabalho, que é medido dividindo-se número de funcionários acidentados por horas de exposição ao risco e Porcentagem de mão-de-obra afastada, que de maneira similar divide o tempo afastado por horas de exposição ao risco.

Ainda de acordo com a tabela 2, observando os níveis de classificação dos indicadores, o porto $\mathrm{Y}$ segmenta os seus em três níveis: estratégico, gerencial e processo. Tais níveis contém diversos indicadores de desempenho, os quais são majoritariamente avaliados mensalmente. Além disso, existe outro nível de classificação que o porto chama de perspectiva, ele faz a divisão em outros três grupos de indicadores: finanças, mercado e processos internos.

Dentro do nível estratégico estão englobados a grande maioria dos indicadores financeiros e alguns de processos internos, além de parte dos de mercado. No nível gerencial estão inseridos essencialmente os indicadores financeiros e de mercado. Já no nível processo estão contidos somente indicadores de processos internos. Fazendo um paralelo com os níveis tradicionais, os níveis estratégico, tático e operacional são correspondentes aos níveis estratégico, gerencial e processo utilizados pelo porto $\mathrm{Y}$, respectivamente. Portanto, verifica-se que para o caso estudado, há adaptações que se fazem necessárias para que os níveis de medição dos indicadores de desempenho se adequem à realidade do porto.

Além da forma de divisão utilizada pelo porto $\mathrm{Y}$, existem diversas outras possíveis variações. Segundo Beresford, Petit e Woo (2011), uma possível forma de se dividir os indicadores de desempenho de um porto é em serviço, que avalia a qualidade serviço prestado externamente, operacional, que se refere a eficiência das operações internas do porto, e logística, que está atrelada ao tempo de espera entre operações. Já para a UNCTAD (2016), destacam-se os indicadores de desempenho operacional, que se concentra principalmente em avaliar a tipologia das cargas e as dimensões do local de manuseio, e financeiro, o qual visa avaliar o desempenho financeiro do porto, tornando bastante claro os fluxos de receitas e custos das atividades. Ainda, para Bichou e Gray (2004), os indicadores podem ser segmentados em macro, os quais estão relacionados à quantificação dos impactos econômicos do porto na região e micro, que tratam das atividades internas do porto, como produtividade.

\section{CONCLUSÃO}

Não é de hoje que a competitividade nos mais diversos mercados ganham força. No setor portuário, importante influenciador do mercado global não é diferente, cada vez mais os portos necessitam se diferenciar para se manterem representativos no mercado. Com isso a inevitabilidade de uma gestão eficiente conquista espaço nas estratégias a serem tomadas. Desta forma os indicadores acabam se tornando fundamentais, muito por transparecer a real situação da entidade com relação às mais diversas atividades, assim como do mercado o qual a mesma está inserida. Assim 
VI CIDESPORT/2019

Congresso Internacional

de Desempenho Portuário

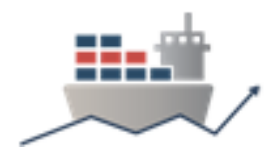

sendo este estudo teve como objetivo comparar conceitos literários a prática de execução, apontando as reais adaptações e usabilidade das métricas propostas.

Tendo em vista uma melhor representatividade da pesquisa, buscou-se uma validação dos indicadores levantados da literatura, como também de métricas utilizadas pelo porto Y. Bem como uma comparação de classificações de indicadores, entre a divisão clássica trazida pela literatura e a proposta de classificação empregada no porto em questão. Com isso foi possível no presente artigo evidenciar e analisar as diferenças existentes entre a teoria e a prática.

Durante todo o estudo ficou clara a importância da utilização de indicadores de desempenho assim como da ambientação de cada porto com o mercado. A abundância de literaturas sobre 0 assunto fortalece uma visão ampla da adequabilidade de cada segmentação e métrica aos ambientes portuários no decorrer do tempo. As várias formas de adquirir a informação e calcular cada indicador e processo acabaram ficando a cargo de responsáveis estratégicos de cada entidade. Os mesmos buscando constantemente um antagonismo das respectivas companhias em entregar valor para o cliente e ao ambiente. Além disto não apenas uma busca por competitividade, mas também um melhor entendimento interno da organização e da esfera do negócio, adquirindo então uma eficiente gestão portuária.

Examinando as limitações decorrentes no estudo, vale destacar o levantamento de dados práticos de apenas um porto em questão, assim como a nebulosidade de dados quantitativos no meio acadêmico. Sugere-se então o aprofundamento e levantamento de mais dados práticos de outras entidades, comparando não apenas bases literárias, mas também situações reais no cenário competitivo, para com isso obter uma avaliação mais prática do desempenho da gestão dos portos.

\section{REFERÊNCIAS}

ALDERTON, Patrick Mitchell; SAIEVA, Giuseppe. Port management and operations. Taylor \& Francis, 2013.

ANTAQ ANUÁRIO ESTATÍSTICO, 2018. http://web.antaq.gov.br/ANUARIO/ Acessado em: 30/06/2019.

ANTAQ, 2018 Disponível em :

<http://portal.antaq.gov.br/index.php/2019/02/12/antaq-divulga-os-numeros-damovimentacao-portuaria-de-2018/> Acesso em: 13/07/2019

ANUÁRIO ESTATÍSTICO DE TRANSPORTES (AET). Disponível em: http://www.transportes.gov.br/images/BIT_TESTE/Publica\%C3\%A7oes/anuario_esta tistico_transportes_2010_2017.pdf. Acesso em junho. 2018.

BALLOU, Ronald H. Logística Empresarial. Transportes. Administração de Materiais. Distribuição Física. Atlas:São Paulo. 2012.

BERESFORD, Anthony KC; PETTIT, Stephen; WOO, Su-Han. Port evolution and performance in changing logistics environments. Maritime Economics \& Logistics, v. 13 , n. 3, p. 250-277, 2011. 
VI CIDESPORT/2019

Congresso Internacional

de Desempenho Portuário

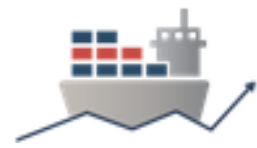

BICHOU, Khalid; GRAY, Richard. A logistics and supply chain management approach to port performance measurement. Maritime Policy \& Management, 2004, 31.1: 47-67.

CARBONE, V. and DE MARTINO, M., 2003. The changing role of ports in supplychain management: an empirical analysis. Maritime Policy and Management, 30 (4), 305-320.

CSCMP - Council of Supply Chain Management Professionals. Supply Chain Management Definitions. Disponível em:

https://cscmp.org/CSCMP/Educate/SCM_Definitions_and_Glossary_of_Terms/CSC MP/Educate/SCM_Definitions_and_Glossary_of_Terms.aspx?hkey=60879588-f65f4ab5-8c4b-6878815ef921 Acesso em 16/05/2019.

CUTRIM, Sérgio Sampaio et al. Seis sigma na operação e logística portuária da vale: estudo de caso no terminal marítimo ponta da madeira. Revista Eletrônica de Estratégia \& Negócios, v. 10, p. 186-210, 2017.

CULLINANE, Kevin; SONG, Dong-Wook. Port privatization policy and practice. Transport Reviews, v. 22, n. 1, p. 55-75, 2002.

DE OLIVEIRA ROCHA, Isa; VIDAL, Leandro Moraes; GUTERRES, Cassio Donadel. Análise da infra-estrutura logística das indústrias exportadoras de grande porte de Santa Catarina. Revista Brasileira de Gestão e Desenvolvimento Regional, v. 7, n. 3, 2011.

DI SERIO, Luiz Carlos; SAMPAIO, Mauro; PEREIRA, Susana Carla Farias. A evolução dos conceitos de logística: um estudo na cadeia automobilística no Brasil.

FORTUIN, L. (1994). Hoofdstuk III: operationele prestatiemeting: onmisbaar op de weg naar voortdurende verbetering. In Jorissen, A. (ed.), Prestatiemeting, naar een betere beheersing van bedrijfsactiviteiten. Antwerpen: maklu uitgevers, pp. 139-177 (in Dutch).

GOMES, E. G. (1999). Integração entre Sistemas de Informação Geográfica e métodos multicritério no apoio à decisão espacial. Rio de Janeiro, RJ. Dissertação (Mestrado) - COPPE, Universidade Federal do Rio de Janeiro, Rio de Janeiro.1999.

GOMES, Eliane Gonçalves, et al. Conceitos básicos do Apoio Multicritério à Decisão e sua aplicação no Projeto Aerodesign. Engevista, 2003, 5.8.

JÚNIOR, José Nauri Cazuza De Sousa; JÚNIOR, Ernesto Ferreira Nobre; PRATA, Bruno De Athayde. Análise da eficiência dos portos da região Nordeste do Brasil baseada em Análise Envoltória de Dados. Sistemas \& Gestão, v. 3, n. 2, p. 74-91, 2009.

KEEDI, S., MENDONÇA, Paulo C.C.Transportes e Seguros no Comércio Exterior. $2^{a}$ ed. São Paulo: Aduaneiras, 2003. 
VI CIDESPORT/2019

Congresso Internacional

de Desempenho Portuário

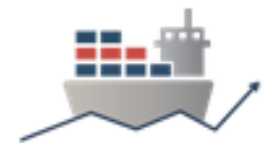

KEEDI, S. Transportes, unitização e Seguros Internacionais de Carga: prática e exercícios. 5 ed. São Paulo, SP: Aduaneiras, 2011.

KOTLER, Philip e ARMSTRONG, Gary. Princípios de Marketing. 9. ed. São Paulo: Prentice Hall, 2003.

Levinson, M., 2008. The Box: How the Shipping Container Made the World Smaller and the World Economy Bigger. Princeton University Press, NJ.

MARTINS, Roberto Antonio; COSTA NETO, Pedro Luiz de Oliveira. Indicadores de desempenho para a gestão pela qualidade total: uma proposta de sistematização. Gestão \& Produção, 1998, 5.3: 298-311.

MINICUCCI, A.Técnicas do trabalho de grupo. São Paulo: Atlas, 2001. MOHRMAN, A. S.; MOHRMAN JR, Allan M. Mudanças organizacionais e aprendizado: Organizando para competir no futuro: estratégias para gerenciar o futuro das organizações. 1995.

PETTIT, S. J. and BERESFORD, A. K. C. (2009). Port development: from gateways to logistics hubs. Maritime Policy \& Management, 36, 253-267.

RAI-Revista de Administração e Inovação, v. 4, n. 1, p. 125-141, 2007.

REICHHELD, Frederick F. Princípios da Lealdade. Como construir relacionamentos com clientes. Rio de Janeiro: Campus, 2001.

ROJAS, Pablo. Introdução à Logística Portuária. E noções de comércio exterior. bookamn: Porto Alegre. 2014

TAKASHINA, Newton Tadashi; FLORES, Mario C. X.. Indicadores da qualidade e do desempenho: como estabelecer metas e medir resultados. Rio de Janeiro:

Qualitymark, 2005.

TEUNE, Henry; PRZEWORSKI, Adam. The logic of comparative social inquiry. New York: Wiley-Interscience, 1970.

UNCTAD (United Nations Conference on Trade and Development). Operation planning in ports. Monograph No. 4. Cardiff, UNCTAD, 1985. Disponível em: <http://unctad.org/en/Docs/ship4944_en.pdf>. Acessado em 17/05/2019

UNCTAD (United Nations Conference on Trade and Development). Linking Performance Indicators to Strategic Objectives. Volume 4. Suiça, UNCTAD, 2016. Disponível em: < https://unctad.org/en/PublicationsLibrary/dtlkdb2016d1_en.pdf>. Acessado em 20/06/2019.

VIEIRA, João Henrique. Modernização da gestão portuária e planejamento operacional integrado por meio de indicadores de desempenho. 2018. Tese de Doutorado. Universidade Federal do Rio de Janeiro.

YIN, R. K. Estudo de caso: planejamento e métodos. 3. ed. Porto Alegre: Bookman, 2005. $212 \mathrm{p}$. 